\title{
Teatro en tiempos de pandemia. Entrevista a la productora mexicana Tercera Llamada
}

\section{Regina Solis Miranda}

University of Sheffield, Reino Unido

rsolis1@sheffield.ac.uk

\author{
Fernando Valcheff García \\ University of St Andrews, Escocia \\ Universidade de Santiago de Compostela, España \\ Universidad Nacional de Mar del Plata, Argentina \\ fvg1@st-andrews.ac.uk
}

\author{
Sara Hermo Nieto \\ Universidade de Santiago de Compostela, España \\ sara.hermo@rai.usc.es
}

Fecha de recepción: 31/07/2020. Fecha de aceptación: 24/08/2020

\begin{abstract}
Resumen
Entrevista realizada en el mes de julio de 2020 a la compañía mexicana de teatro Tercera Llamada que recoge los testimonios de Ana Bracho, productora y socia fundadora, y Quetzalli Cortés, actor y director, acerca del proyecto de teatro virtual \#LiveOnlineNow. Esta modalidad de puesta en escena de obras en vivo a través de la plataforma Zoom fue implementada por la compañía a comienzos de abril de 2020 como respuesta a las medidas de confinamiento social que obligaron a la suspensión de los espectáculos teatrales presenciales como consecuencia de la pandemia de COVID-19. Dialogamos con ambos acerca de las motivaciones, procesos y experiencias vinculados con esta práctica, los cambios en la implementación y recepción de las performances con respecto al teatro tradicional y los desafíos de cara a las dificultades presentes y futuras que enfrenta el sector.
\end{abstract}




\title{
Theatre in Times of the Pandemic. Interview with the Mexican Production Company Tercera Llamada
}

\begin{abstract}
This interview, conducted in July 2020 with the Mexican theatre company Tercera Llamada, collects the testimonies of Ana Bracho, producer and founding partner, and Quetzalli Cortés, actor and director, regarding the company's \#LiveOnlineNow virtual theatre project. This format of staging live theatre through the Zoom platform was implemented by the company in early April 2020 as a response to the social confinement measures that suspended face-to-face performances due to the COVID-19 pandemic. The conversation focuses on the motivations, processes and experiences involved in this practice, the differences in its implementation and reception in comparison to traditional theatre performances, and the current and future challenges in the sector.
\end{abstract}

Keywords: Tercera Llamada, Virtual Theatre, Online Theatre, Confined Theatre, Bracho, Cortés.

\section{— ¿Qué les motivó a llevar el teatro a la virtualidad?}

Quetzalli Cortés: Sin duda una necesidad básica, que creo compartimos todos los creativos, por seguir creando. También están presentes las ganas de ayudar desde donde nos toca.

Ana Bracho: Teníamos ganas de poner la cabeza y el corazón a trabajar en lo que más nos gusta y no dejar tanto espacio al miedo y a la incertidumbre. De encontrar maneras para seguir haciendo lo que amamos y de compartirlo con quien tuviera ganas de conectarse a las funciones y así permitir pequeños momentos de comunión a pesar de las barreras del confinamiento.

\section{- ¿Quiénes participan en el proceso de redacción de los guiones? ¿Cómo surgen las ideas?}

QC: Los textos son de nuestros dramaturgos. De parte nuestra solo hay una invitación inicial y algunas provocaciones. Parte del juego es que los textos sean nuevos, cortos (aproximadamente de quince minutos) y escritos para que desde el origen, dentro de su mismo universo ficticio, estén sucediendo frente a una cámara de Zoom, de un celular o quizá una cámara de seguridad.

\section{- ¿Cómo describirían la preproducción? ¿Cuál es la dinámica de la preparación de las puestas y los ensayos?}

QC: Nos reunimos para votar por los textos que habrán de montarse. Una vez aprobados buscamos un director que creamos adecuado. Además de actores y actrices. Cuando el equipo está formado se hace una primera lectura con todos y a partir de ese momento el director toma control creativo. Cada director trabaja de manera diferente, entre él y los actores toman decisiones con respecto al lugar (escenografía), vestuario, iluminación, etcétera. Todo esto se hace por Zoom y de acuerdo a las posibilidades y elementos que los actores tengan en casa (otra regla del juego). Normalmente es un proceso de tres semanas para poder estrenar. 


\section{- ¿Cómo varía la experiencia de la actuación virtual en contraste con el espectáculo en vivo?}

QC: Durante el proceso creativo el trabajo es híbrido entre la profundidad en el trabajo actoral del teatro, en donde es el actor quien cuenta la historia, pero también se integra el aspecto visual del encuadre y los planos del cine. Pero, en este caso, el actor mismo es el camarógrafo. Justo antes de empezar la función, el consenso general entre los actores y actrices es que los nervios previos son los mismos que en el teatro. Quizá porque es en vivo y uno espera que el público llegue y que no haya fallas durante la representación. Durante ella, no tienes la retroalimentación del público, así que en ese aspecto se parece más al cine o a la televisión, en donde depositas tu confianza plena en el trabajo previo y la dirección. Al finalizar, y al contrario de representar en un recinto, al terminar la función, estás en tu casa. Toda la energía se ha quedado ahí, contigo; no existe ese flujo que ocurre naturalmente cuando te presentas en el teatro.

\section{- ¿Cuál es el promedio de asistencia a cada función? ¿Cómo valorarían la recepción de la audiencia?}

QC: Hemos determinado cerrar las funciones cuando se haya llegado aproximadamente a los trescientos espectadores y en la mayoría hemos llenado. Los comentarios han sido muy positivos. La gente agradece mucho tener esta opción. Personalmente, los comentarios que hablan sobre anécdotas muy personales de por qué se conmovieron con este proyecto, como quienes nos ha comentado que ven las funciones mientras están batallando con el COVID, o las reacciones de tuvieron sus niños al ver nuestra obra infantil, las fotografías de cómo y con quién ven las obras, etc.

\section{- ¿Por qué podemos seguir hablando de teatro al nombrar este tipo de espectáculos virtuales? ¿Qué hace que continúe siendo teatro?}

QC: De manera personal, creo que definitivamente tiene características individuales suficientes para tener un nuevo nombre, es decir, Teatro como tal, no es, tan solo porque no es presencial. También es verdad que comparte muchas características con el mismo y que todos los involucrados somos gente que hace teatro. A mí lo que me interesa es crear. La discusión sobre cuál es su nombre se puede tener en otro momento, o en paralelo, siempre y cuando el definir el nombre no detenga, limite u obstaculice el hecho mismo.

AB: Sumando a lo que dice Quetz, como producción hemos procurado incluir y respetar ciertas convenciones del teatro convencional para hacer de esta nueva manera, una experiencia rica y que claramente sea diferente a la del cine o la televisión (más allá de la nomenclatura de este tipo de teatro). En este sentido, el hecho de que las funciones sean en vivo quizá es uno de los elementos que más resaltaría. Y retomando algo que mencionó una de nuestras escritoras en una de las conferencias virtuales de prensa, el arte durante el transcurso de la historia ha ido reinventándose y adaptándose según las condiciones sociales, culturales, tecnológicas y demás que han ido sucediendo. Creo que esta propuesta es una adaptación más a esto que estamos viviendo. Veremos cómo sigue el mundo y qué va pasando con el teatro. 
-Entre abril y julio han montado quince obras a lo largo de catorce semanas. Han trabajado con ocho directores, nueve escritores y veintiseis actorxs, logrando alcanzar alrededor de dieciocho mil seiscientas pantallas (Fuente: Redes sociales de Tercera Llamada), calguna experiencia en particular que quisieran resaltar?

QC: Hay demasiadas; cada equipo que se junta, convive durante al menos seis semanas. No es una computadora a la que se le ingresa una operación matemática que tiene que resolver, son seres humanos que se juntan para desentrañar un texto en busca de su esencia, su humanidad, lo risible y lo trágico, en fin, está lleno de vida.

AB: Sumaría la felicidad y completa entrega de los equipos, creo que para todos los creadores ha sido un respiro y un motor tener estos espacios para crear y seguir haciendo lo que nos mueve. Como anécdota: tenemos una slide que dice: "Estamos teniendo problemas técnicos, en breve regresamos". Suponiendo que en algún momento la tecnología nos jugaría chueco, hasta ahora (y toco madera), no hemos tenido que usarla.

\section{- Hemos notado que, a diferencia del inicio de estos montajes, ahora están pidiendo una donación. ¿Qué cambió?}

QC: Al empezar el proyecto había una intención muy inmediata de responder. No pensamos en su continuidad y, sin duda, hacerlo y seguir haciéndolo implica un gasto económico. Después de mucho discutir, hemos optado por los donativos porque es una opción abierta a que el espectador tome la decisión de acuerdo a si tiene o no las posibilidades económicas para ello. Nos encanta que quien no pueda costearlo, pueda verlo porque alguien más de su comunidad aportó por él o ella. Hacer teatro cuesta, en el panorama de la ciudad de México hay muchas opciones gratuitas o con precios muy accesibles, pero esto no debe tomarse como una relación proporcional entre la manufactura y el costo del boleto, o como un indicador de calidad. Esa accesibilidad se debe generalmente a un subsidio o una beca, es decir; alguien está pagando tu boleto, aunque no seas consciente de ello. Tercera Llamada \#LiveOnlineNow no tiene ningún tipo de subsidio, ni patrocinadores. Creemos que, al abrir la opción del donativo, lo hagas o no, generamos ese necesario reconocimiento a la labor de todos los involucrados. Hemos sido insistentes con el mensaje de que el elenco que ves en función es solo la cara de un equipo amplio que incluye dramaturgos, directores, operadores, diseñadores, prensa, productores, etc. a quienes nos parece importante retribuir. Por decirlo de manera coloquial "todos ellos comen", y su labor es importantísima. Después de todo, qué sería de nosotros en este encierro sin una película, sin música, sin un libro, un videojuego...

\section{- ¿Qué panorama se plantea para el futuro del sector artístico-cultural ante la precarización laboral que se ha sufrido a nivel mundial?}

QC: Ya estamos en una crisis importante. El cine, el teatro y la televisión están prácticamente detenidos. Casi todos nosotros somos trabajadores independientes que recibimos pago por el proyecto en turno. Al regresar ¿cuántos estarán en la capacidad económica de seguir produciendo? Más aún cuando en muchos proyectos no se puede recuperar la inversión con el teatro al $30 \%$ de su capacidad... El panorama es muy incierto. También tenemos la esperanza de que este tipo de proyectos ayude a que los espectadores que no han ido al teatro se maravillen con sus posibilidades y que ellos, junto con los asiduos del teatro, regresen en el momento exacto en el que se nos permita hacerlo. 
- ¿Perciben alguna diferencia en cuanto a la reacción del sector artístico-cultural en Latinoamérica y en otras partes del mundo?

QC: No realmente. Es decir, obviamente cada país, incluso cada producción tiene sus particularidades pero a nivel esencial nos une justamente reaccionar, responder, enfrentar esta crisis desde nuestra trinchera y con los elementos que tenemos a nuestra disposición.

\section{- ¿Están en contacto con otras iniciativas similares en la región? ¿Conocen alguna otra?}

QC: Sí, en la comunidad teatral de la ciudad de México nos conocemos todos.

AB: Los que hacemos teatro somos pocos y eso ayuda. Esto en Ciudad de México; sería interesante conocer otros esfuerzos en el resto de la República. Sé que hay gente en Tijuana que están haciendo lecturas en vivo por ejemplo, o contando cuentos, pero no hemos estado en contacto con ellos.

\section{- ¿Algún comentario que deseen agregar?}

QC: No sé pierdan las funciones, generalmente los jueves y sábados a las 8, 8:45 y 9:30pm (hora del centro de México). Las contraseñas para entrar y toda la información de las obras está en las redes de Tercera Llamada: @3allamada en Instagram, @3allamadateatro en Twitter y @TerceraLlamadaTeatroMexico en Facebook.

AB: Nos encantará escuchar de opciones similares en el resto del mundo. Se trata de pulir y cada vez lograr mejores experiencias de teatro virtual.
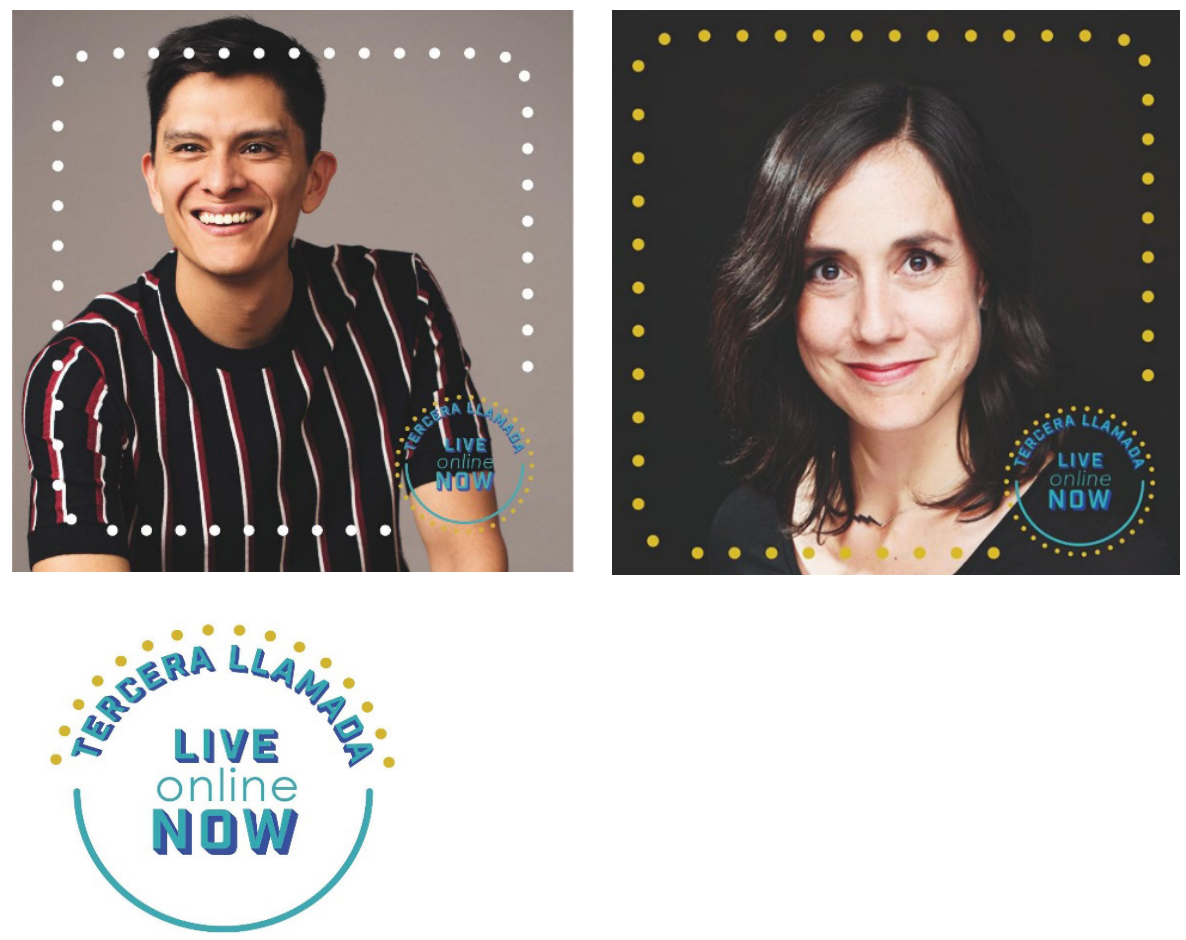

Fotografías: Redes sociales de Tercera Llamada. 